\title{
SISTEM PENERIMAAN BEASISWA MENGGUNAKAN METODE SAW SEBAGAI PENUNJANG KEPUTUSAN
}

\author{
Mardiana*1) $^{* 1}$, Zulvi Kurniawan Aslam ${ }^{2)}$, Dede kurniawan ${ }^{3)}$ \\ ${ }^{1}$ Program Studi Akuntansi Universitas Raharja, ${ }^{2,3}$ Program Studi Teknik Informatika Universitas \\ Raharja \\ *1'mardiana@raharja.info, ${ }^{2}$ zulvi.kurniawan@raharja.info, ${ }^{3}$ dedekurniawan@raharja.info
}

\begin{abstract}
Abstrak
Teknologi dan ilmu pengetahuan mengalami perkembangan yang cukup meningkat. Dengan kemajuan ilmu pengetahuan dan teknologi yang serba canggih dan modern, komputer menjadi salah satu alat terpenting untuk membantu manusia mengatasi berbagai permasalahan dalam pemberian beasiswa. Tujuan dari penelitian ini adalah untuk mendapatkan beasiswa dimana saat ini proses pemberian beasiswa masih manual. Metode yang digunakan dalam penelitian ini adalah metode SAW (Simple Additive Weight) agar dapat mempermudah proses pemberian beasiswa secara obyektif berdasarkan bobot dan kriteria penilaian yang telah ditentukan. Dari hasil analisis dan observasi yang dilakukan dapat diketahui bahwa beasiswa yang diberikan masih kurang memadai sehingga menghambat proses pemberian beasiswa, maka penulis bermaksud untuk merancang sistem pendukung keputusan penilaian kinerja pegawai dengan menggunakan metode SAW (Simple Additive Weight). Data yang digunakan untuk mengolah desain antara lain data rapor, data yatim piatu, data masyarakat miskin atau kurang mampu. Hasil yang didapat dalam penelitian ini menunjukkan bahwa program penerimaan beasiswa memerlukan suatu sistem yang memberikan kemudahan bagi staf dan guru, menghemat waktu dan mudah untuk dijalankan
\end{abstract}

Kata Kunci : Metode SAW, Pendukung Keputusan, Penerimaan Beasiswa

\begin{abstract}
Technology and science have experienced quite increasing developments. With advances in science and technology that are completely sophisticated and modern, computers have become one of the most important tools to help humans overcome various problems in providing scholarships. The purpose of this research is to obtain scholarships where currently the scholarship granting process is still manual. The method used in this research is the SAW (Simple Additive Weight) method in order to facilitate the process of giving scholarships objectively based on the weights and assessment criteria that have been determined. From the results of the analysis and observations made it can be seen that the scholarships given are still inadequate so that it hinders the scholarship award process, so the authors intend to design a decision support system for employee performance appraisal using the SAW (Simple Additive Weight) method. The data used to process the design include report card data, orphan data, data on the poor or underprivileged. The results obtained in this study indicate that the scholarship acceptance program requires a system that makes it easy for staff and teachers, saves time and is easy to run.
\end{abstract}

Keywords: SAW Method, Decision Support, Scholarship Acceptance 


\section{Pendahuluan}

Dengan perkembangan teknologi yang sangat pesat, teknologi memiliki peran penting dalam membantu dan menyelesaikan pekerjaan manusia. Komputer adalah salah satu opsi untuk perangkat teknologi canggih yang memungkinkan dukungan untuk menangani pekerjaan dan menangani arus informasi dalam jumlah besar dan membantu dalam membuat keputusan terbaik.

Pemberian bantuan belajar berupa beasiswa juga diberikan kepada peserta didik di sekolah. Beasiswa yang diberikan antara lain berupa Bantuan Belajar Mengajar (BBM) yang diberikan kepada peserta didik kurang mampu. Dalam penentuan penerimaan beasiswa masih digunakan metode manual. Hal tersebut mengakibatkan pengelolaan data beasiswa menjadi tidak efisien dan efektif, terutama dari segi waktu dan banyaknya proses berulang yang seharusnya tidak dipersingkat. Pengelolaan data beasiswa yang belum menggunakan database sehingga belum terakumulasi secara optimal menjadi penyebab kesulitan dalam pengolahan data masukan. Sehingga butuh waktu lama untuk menentukan penerimaan beasiswa. Oleh karena itu, diperlukan suatu sistem proses penerimaan beasiswa, sehingga dapat mempersingkat waktu seleksi dan dapat meningkatkan kualitas keputusan dalam penentuan beasiswa bantuan belajar mengajar (BBBM).

Tujuan dari penelitian ini adalah membangun sistem pendukung keputusan seleksi penerimaan beasiswa dengan menggunakan metode Simple Additive Weighting (SAW) yang dapat membantu para pihak dalam pengambilan keputusan dengan cara memilih proses penerimaan beasiswa secara mudah dan cepat serta memberikan hasil yang akurat dan tepat.

\section{Landasan Teori}

\section{Sistem Pendukung Keputusan}

Limbong dkk (2020:1), SPK adalah adalah sistem berbasis model yang terdiri dari prosedur dalam pengolahan data dan pertimbangannya untuk membantu manajer dalam mengambil keputusan, untuk mencapai tujuannya sistem harus sederhana, mudah dikendalikan, mudah beradaptasi, dan lengkap.[1]

\section{Metode Simple Additive Weighting (SAW)}

(Veronika dan Ginting, 2020 yang dikutip oleh Poningsih dkk, 2020:63) metode SAW merupakan singkatan dari Simple Additive Weighting yang digunakan untuk menentukan nilai yang sudah terbobot dengan mencari nilai dari penjumlahan terbobot dari semua alternative untuk semua kriteria dan atribut. Metode ini mampu menganalisa alternatifalternatif yang ada untuk menghasilkan suatu keputusan dengan mudah.

\section{Keuntungan dari Metode Simple Additive Weighting (SAW)}

1. Perhitungan metode SAW yang hanya memiliki 4 tahapan yaitu penentuan kriteria, penentuan kesesuaian rating, pembuatan matriks keputusan dan rangking yang diperoleh dari penjumlahan perkalian ternormalisasi R.

2. Menentukan nilai bobot untuk masing-masing atribut kemudian dilanjutkan dengan proses perankingan yang akan memilih alternatif terbaik dari sejumlah alternatif

3. Penilaian akan lebih tepat karena didasarkan pada nilai kriteria bobot preferensi yang telah ditentukan

4. Adanya perhitungan normalisasi matriks sesuai dengan nilai atributnya (termasuk benefit dan cost) 


\section{Kerugian dari Metode Simple Additive Weighting (SAW)}

1. Perhitungan dilakukan dengan menggunakan crips dan bilangan fuzzy

2. Terdapat perbedaan perhitungan matriks normalisasi menurut nilai atribut (antara nilai benefit dan cost)

\section{Literature Review}

1. Liesnaningsih dkk, "Sistem Pendukung Keputusan Penerima Beasiswa Berbasis WEB Menggunakan Metode Simple Additive Weighting (SAW) pada Pondok Pesantren Daarul Ahsan". Hasil penelitian ini membutuhkan sistem pendukung keputusan. Dimana model yang digunakan dalam sistem pendukung keputusan ini adalah simple additive weighting, metode ini sering juga dikenal dengan metode penjumlahan terbobot (weighted sum), konsep dasar dari metode ini adalah mencari penjumlahan terbobot dari peringkat kinerja untuk setiap alternatif pada semua atribut. Metode ini dipilih karena mampu memilih alternatif terbaik dari sejumlah alternatif, dalam hal ini alternatif yang dituju adalah yang berhak mendapatkan beasiswa berdasarkan kriteria yang ditentukan.

2. Wattimena dkk, "Sistem Pendukung Keputusan Penerimaan Beasiswa Bidikmisi Menggunakan Metode SAW (Studi Kasus : Bag. Kemahasiswaan Universitas Victory Sorong)". Hasil dari penelitian ini sistem pendukung keputusan penerimaan beasiswa perlu diterapkan agar dapat membantu mempercepat dan mempermudah pemberian beasiswa dalam pengambilan keputusan yang tepat bagi mahasiswa yang berhak menerima beasiswa dan yang tidak..

3. Rohmatin dkk, "Sistem Pendukung Keputusan Penentuan Calon Penerima Beasiswa Menggunakan Metode Simple Additive Weighting (SAW) Berbasis Web". Hasil yang diperoleh dari penelitian ini bertujuan untuk meranking nilai bobot masing-masing atribut yang menjadi persyaratan dalam penentuan beasiswa. Tingkat akurasi antara jawaban yang diperoleh dari sistem dan informasi yang diminta oleh pengguna dapat ditentukan dengan menguji perbandingan hasil perhitungan pada sistem dengan hasil perhitungan manual.

4. Faiz, "Pengembangan Sistem Pendukung Keputusan Untuk Seleksi Penerimaan Beasiswa Dengan Metode Saw Dan Topsis : Studi Kasus Universitas Muhammadiyah Tangerang". Hasil penelitian dengan menggabungkan metode Saw dan Topsis berhasil dibangun sehingga hasil yang diberikan lebih tepat sasaran dan dapat mempercepat waktu dalam pemilihan data penghargaan beasiswa.

5. Laurentinus, "Sistem Pendukung Keputusan Seleksi Mahasiswa Penerima Beasiswa menggunakan Metode Fuzzy Multiple Attribute Decision Making (FMADM) dan Simple Additive Weighting (SAW)". Hasil dari penelitian ini adalah bagian kemahasiswaan dapat lebih akurat, efektif dan efisien dalam memberikan beasiswa sehingga yang mendapatkan beasiswa tersebut adalah mahasiswa yang paling layak.

Dari kelima tinjauan pustaka di atas, dapat disimpulkan bahwa sistem pendukung keputusan penerimaan beasiswa dengan metode SAW sangat diperlukan karena memudahkan sekolah dalam mengambil keputusan tentang pemberian beasiswa yang berhak mendapatkan beasiswa. 


\section{Metode Penelitian}

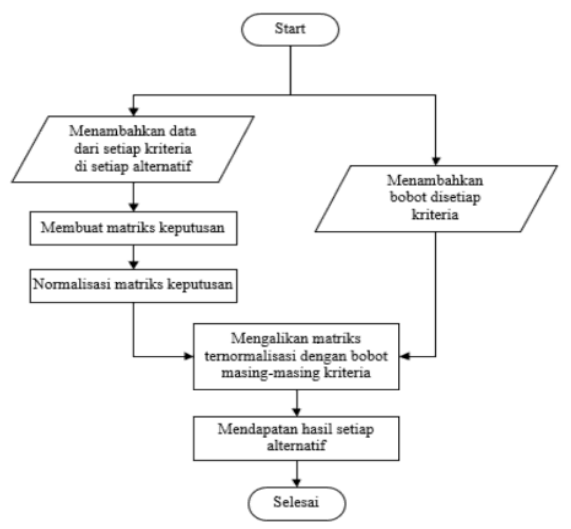

Gambar 1. Algoritma metode Simple Additive Weighting (Saputra dan Lusia, 2020:22)

Metode penelitian ini menggunakan Simple Additive Weighting (SAW) menurut susanto (2020:8), Metode Simple Additive Weighting (SAW) sering disebut dengan istilah metode penjumlahan terbobot. Konsep dasar metode Simple Additive Weighting (SAW) adalah mencari penjumlahan terbobot dari rating kinerja pada setiap alternative dari semua atribut.

Adapun Langkah-langkah perhitungan menggunakan metode Simple Additive Weighting (SAW) adalah :

1. Menentukan kriteria-kriteria yang akan dijadikan acuan dalam pengambilan keputusan, yaitu $\mathrm{Ci}$

2. Menentukan rating kecocokan setiap alternatif pada setiap kriteria

3. Membuat matriks keputusan berdasarkan kriteria (C), kemudian melakukan normalisasi matriks berdasarkan persamaan yang disesuaikan degan jenis atribut (atribut keuntungan ataupun atribut biaya) sehingga diperoleh matriks ternormalisasi R, berikut ini rumusnya.

$$
r_{i j}\left\{\begin{array}{l}
\frac{X_{i j}}{M^{X_{i j}}} \text { Jika adalah atribut keuntungan (benefit) } \\
\frac{\operatorname{Min}^{X_{i j}}}{X_{i j}} \text { Jika adalah atribut biaya (cost) }
\end{array}\right.
$$

Rij : Nilai rating kinerja ternormaliasasi

$\mathrm{Xij} \quad$ : Nilai atribut yang dimiliki dari setiap kriteria

Max Xij : Nilai tersebar dari setiap kriteria i

Min Xij : Nilai terkecil dari setiap kriteria i

Benefit : Jika nilai terbesar adalah terbaik

Cost : Jika nilai terkecil adalah terbaik

Hasil akhir diperoleh dari proses perankingannya itu penjumlahan dari perkalian matriks ternormalisasi $\mathrm{R}$ dengan vector bobot sehingga diperoleh nilai terbesar yang dipilih sebagai alternative terbaik (A) sebagai solusi, berikut rumus perankingannya.

$$
V i=\sum_{j=1}^{n} W_{J} r_{i j}
$$


Keterangan :

Vi : Ranking untuk setiap alternative

$\mathrm{Wj} \quad$ : Nilai bobot dari setiap kriteria

Rij : nilai ranking kinerja ternormalisasi

\section{Hasil Dan Pembahasan}

Langkah langkah untuk menetukan perhitungan untuk Penerimaan Beasiswa menggunakan Metode Simple Additive Weighting (SAW), yaitu:

1. Penentuan kriteria

Langkah kesatu (1) menentukan kriteria yang akan digunakan sebagai acuan dalam pengambilan Penentuan kelayakan penerima Beasiswa yaitu Ci.

\begin{tabular}{|l|l|}
\hline Kriteria & Keterangan \\
\hline C1 & Ranking 1 \\
\hline C2 & Yatim \\
\hline C3 & Kurang Mampu \\
\hline
\end{tabular}

Tabel 1. Penentuan kriteria dalam menentukan beasiswa

2. Memberikan Nilai Bobot

Langkah kedua (2) memberikan nilai bobot atau tingkat kepentingan (W) setiap kriteria. Bobot kriteria yang akan digunakan dalam penentuan beasiswa adalah sebagai berikut :

\begin{tabular}{|l|l|l|}
\hline Kriteria & Tingkat Kepentingan & Bobot \\
\hline C1 & Sangat Tinggi & $50 \%$ \\
\hline C2 & Tinggi & $30 \%$ \\
\hline C3 & Sedang & $20 \%$ \\
\hline
\end{tabular}

Tabel 2. penentuan bobot dalam menentukan beasiswa

3. Memberikan Skor alternatif pada setiap kriteria:

\begin{tabular}{|l|l|l|l|}
\hline \multicolumn{5}{|c|}{ Kriteria } \\
\hline Altematif & C1 & C2 & C3 \\
\hline Alawi & 85 & 70 & 65 \\
\hline Fuad & 80 & 75 & 62 \\
\hline Yoga & 82 & 73 & 64 \\
\hline Wahyu & 90 & 72 & 61 \\
\hline
\end{tabular}

Tabel 3. nilai alternative pada kriteria

Setelah nilai alternative dibuat maka selanjutnya pembuatan normalisasi menggunakan perhitungan sebagai berikut: 
$r_{11}=\max \frac{85}{(85: 80: 82: 90)}=\frac{85}{90}=0,94$

$r_{32}=\max \frac{73}{(70: 75: 73: 72)}=\frac{73}{75}=$

0,97

$r_{21}=\max \frac{80}{(85: 80: 82: 90)}=\frac{80}{90}=0,88$

$r_{42}=\max \frac{72}{(70: 75: 73: 72)}=\frac{72}{75}=$

0,96

$r_{31}=\max \frac{82}{(85: 80: 82: 90)}=\frac{82}{90}=0,91$

$r_{13}=\max \frac{65}{(65: 62: 64: 61)}=\frac{65}{65}=$

1

$r_{41}=\max \frac{90}{(85: 80: 82: 90)}=\frac{90}{90}=1$

$r_{23}=\max \frac{62}{(65: 62: 64: 61)}=\frac{62}{65}=$

0,95

$r_{12}=\max \frac{70}{(70: 75: 73: 72)}=\frac{70}{75}=0,93$

$r_{33}=\max \frac{64}{(65: 62: 64: 61)}=\frac{64}{65}=$

0,98

$r_{21}=\max \frac{80}{(85: 80: 82: 90)}=\frac{80}{90}=0,88$

$r_{43}=\max \frac{61}{(65: 62: 64: 61)}=\frac{61}{65}=$

0,93

Setelah dinormalisasi, langkah selanjutnya adalah menyusun nilai-nilai yang dinormalisasi menjadi matriks:

$$
R=\left[\begin{array}{ccc}
0,94 & \breve{0,93} & 1 \\
0,88 & 1 & 0,95 \\
0,91 & 0,97 & 0,98 \\
1 & 0,96 & 0,93
\end{array}\right]
$$

Bobot yang telah ditentukan $(\mathrm{Wj})$ oleh sekolah:

$\mathrm{C} 1=0,5$

$\mathrm{C} 2=0,3$

$\mathrm{C} 3=0,2$

Kemudian tahap selanjutnya adalah mencari hasil (V) dari perhitungan normalisasi diatas, dalam mencari perhitungan (V) akan menggunakan perhitungan sebagai berikut:

$$
\begin{gathered}
V 1=(0.5)(0.94)+(0.3)(0.93)+(0.2)(1)=0.949 \\
V 2=(0.5)(0.88)+(0.3)(1)+(0.2)(0.95)=0.93 \\
V 3=(0.5)(0.91)+(0.3)(0.97)+(0.2)(0.98)=0.942 \\
V 4=(0.5)(1)+(0.3)(0.96)+(0.2)(0.93)=0.974
\end{gathered}
$$

Dari perhitungan diatas terlihat bahwa nilai terbesar dari 4 data tersebut berada pada V4 dengan nilai 0,974, sehingga alternatif yang dipilih sebagai alternatif terbaik adalah V4. Dengan kata lain, Wahyu akan terpilih sebagai penerima beasiswa 


\section{Kesimpulan}

Berdasarkan hasil analisis yang dilakukan di SMK Miftahul Jannah menggunakan metode SAW, terlihat bahwa siswa di SMK Miftahul Jannah tergolong siswa yang kurang mampu secara finansial dalam membiayai sekolahnya. Dengan metode SAW, sekolah dapat menentukan siswa mana yang benar-benar layak mendapatkan bantuan beasiswa yang diperoleh adalah V4 dengan nilai akhir 0,974, dimana V4 adalah siswa bernama Wahyu yang menerima beasiswa. Dalam pengambilan keputusan perlu ada hasil persaingan, jika jumlah penerima beasiswa lebih dari satu orang siswa. Dari kesimpulan di atas, penelitian selanjutnya disarankan untuk memperbanyak sampel penelitian dengan menggunakan kombinasi metode lain.

\section{Daftar Pustaka}

Laurentinus, L. (2019). Sistem Pendukung Keputusan Seleksi Mahasiswa Penerima Beasiswa menggunakan Metode Fuzzy Multiple Attribute Decision Making (FMADM) dan Simple Additive Weighting (SAW). InfoTekJar (Jurnal Nasional Informatika Dan Teknologi Jaringan), 4(1), 133-137. doi:10.30743/infotekjar.v4i1.1559

Liesnaningsih, L., Taufiq, R., Destriana, R., \& Suyitno, A. P. (2020). Sistem Pendukung Keputusan Penerima Beasiswa Berbasis WEB Menggunakan Metode Simple Additive Weighting (SAW) pada Pondok Pesantren Daarul Ahsan. Jurnal Informatika Universitas Pamulang, 5(1), 54. doi:10.32493/informatika.v5i1.4664

Limbong, Tonni dkk. 2020. Sistem Pendukung Keputusan : Metode \& Implementasi. Medan : Yayasan Kita Menulis

Poningsih, dkk. 2020. Sistem Pendukung Keputusan : Penerapan dan 10 Contoh Studi Kasus. Medan : Yayasan Kita Menulis

Rohmatin, Y., Kusrini, W., Noor, A., \& Fathurrahmani, F. (2020). Sistem Pendukung Keputusan Penentuan Calon Penerima Beasiswa Menggunakan Metode Simple Additive Weighting (SAW) Berbasis Web. Jurnal Sains Dan Informatika, 6(1), 102-111. doi:10.34128/jsi.v6i1.219

Saputra, M, Harry, K., \& Lusia Violita Aprilian. 2020. Belajar Cepat Metode SAW. Bandung : Kreatif Industri Nusantara

Susanto, Ferry. 2020. Pengenalan Sistem Pendukung Keputusan. Yogyakarta : Deepublish Publisher

Wattimena, J. N., Urbasa, D. S., \& Manuputty, P. (2020). Sistem Pendukung Keputusan Penerimaan Beasiswa Bidikmisi Menggunakan Metode Saw (Studi Kasus : Bag. Kemahasiswaan Universitas Victory Sorong). Electro Luceat, 6(2), 124-132. doi:10.32531/jelekn.v6i2.224 